\title{
Validity and Reliability of the Indonesian Version Gross Motor Function Measure to Measure Gross Motor Function in Cerebral Palsy Children
}

\author{
Selly C Anggoro ${ }^{1}$, Amendi Nasution ${ }^{1}$, Luh K Wahyuni, Aria Kekalih ${ }^{2}$ \\ ${ }^{1}$ Department of Physical Medicine and Rehabilitation, Faculty of Medicine University of Indonesia \\ 2 Department of Community Medicine, Faculty of Medicine University of Indonesia
}

\begin{abstract}
S
Objectives: Cerebral palsy (CP) is the most physical disabling disease in children. Gross motor capacity in CP usually measured and evaluated by Gross Motor Function Measure (GMFM), a standardized observational instrument to evaluate gross motor function. Studies showed GMFM reliable, valid, and responsive to change of $\mathrm{CP}$ gross motor function. This research aims to examine validity and reliability of GMFM translated into Indonesian.

Methods: Cross sectional study with consecutive sampling of CP children aged 2-15 years came to pediatric rehabilitation clinic at RSCM Medical Rehabilitation Department or YPAC Jakarta. Subjects classified by age, type, anatomical distribution, and severity. Gross motor function evaluated with 88 GMFM items translated into Indonesian. Inter-rater evaluated gross motor function through video records. Criterion validity tested by correlation coefficient, construct validity tested by comparing GMFM item with dimension total scores and GMFM total score with corrected Spearman correlation. Inter-rater reliability tested by unpaired T-test, internal consistency by alpha Cronbach.

Results: Thirty one CP children with mean age 7 years 11 months, mean GMFM score $58.40(\mathrm{SD}=49.09)$. No significant difference of all GMFM dimensions; almost all GMFM items obtained from interrater evaluation. Good internal consistency (alpha Cronbach 0.884 ) and good criterion validity of all dimensions; inter-item and total correlations good to strong $(\mathrm{r}=0.523-0.859)$.

Conclusion: GMFM Indonesian has good to strong criterion validity. Construct validity of all dimensions was quite good. Internal consistency was good. No significant difference between inter-raters showed GMFM inter-rater reliability good enough.
\end{abstract}

Keywords: Cerebral palsy, gross motor function, gross motor function measure, validity, reliability.

\section{INTRODUCTION}

The prevalence of Cerebral Palsy (CP) in the United States in 2002 is about 3.6 per 1,000 children of school age, ${ }^{1}$ whereas in 2007 the prevalence of CP in Sweden is from 2.4 to 3 per 1000 children aged 4-11 years, except

Received in March 2012 and accepted for published in April 2012.

Correspondence address : Selly C Anggoro, Persahabatan Hospital, Jl. Persahabatan Raya no.1. Jakarta Timur, Indonesia. Email : sellywijayasurya@ yahoo.com for cases of CP postnatal. ${ }^{2}$ Data from medical record in the Department of Physical Medicine and Rehabilitation at Cipto Mangunkusumo hospital (RSCM), ${ }^{3}$ found 303 new and old cases of CP or $23.76 \%$ of all outpatients of Paediatric Rehabilitation clinic of the Medical Rehabilitation Department throughout the year 2010.

Bax et al. $2005^{4-5}$ defines CP as a group of disorders of movement and posture developments, leading toactivity limitations, duetonon-progressive disorder of the brain of fetus or the developing baby. Motor disorders are often accompanied by disturbances of sensation, perception, cognition, communication, behavior, and epilepsy or 
secondary musculoskeletal problems.

Etiology of CP is multiple, ${ }^{6}$ with its risk factors can be divided into 3 periods of the prenatal, perinatal and postnatal. ${ }^{2}$ A modified neurological classification system classifies CP in three categories, i.e. $\mathrm{CP}$ with pyramidal signs or spastic $\mathrm{CP}, \mathrm{CP}$ with extrapyramidal signs (dyskinetic and ataxic $\mathrm{CP}$ ), and mixed type. Spastic CP is classified according to topography or distribution of the affected body part, which are monoplegic, diplegic, hemiplegic, triplegic, and quadriplegic. ${ }^{7}$ Palisano et al. ${ }^{8,9}$ classifies the degree of $\mathrm{CP}$ according to their functional motor skills with the objective functional scale of Gross Motor Function Classification System (GMFCS). There are 5 categories level of function, which are GMFCS level I to $\mathrm{V}$ for four age groups: before 2 years, 2-4 years, 4-6 years, 6-12 years..$^{9-10}$

According to the International Classification of Functioning, Disability and Health (ICF-WHO 2001), ${ }^{11}$ the function of a human being can be classified, measured, and influenced in various dimensions, including the body structures and the body functions, as well as their activities and participation. Environmental factors, health and personal factors can also influence the children in running their functions.

$\mathrm{CP}$ affects the neurological development and the function of children in different levels, which will also influence the degree of impairments, activities and participation of the children. Assessment of activities of CP children in the form of gross motor capacity is generally examined and evaluated with the Gross Motor Function Measure or GMFM developed by Russell et al., 2002. GMFM is a standardized observational instrument designed to evaluate changes in gross motor function in CP children. GMFM was developed by the Gross Motor Measures Group and used both in clinics and researches. GMFM is designed to assess how a child is able to do his/ her physical activity, and not to measure how well these activities can be performed. ${ }^{12}$

There are two versions of GMFM, the original version of GMFM- 88 and the latest version GMFM-66, which has fewer items yet assumed to be unidimensional. These items cover the spectrum of activities ranging from the position of lying, rolling, sitting, crawling, standing, to walking, running and jumping skills. Whole items can be achieved by a 5-year-old boy with typical development of motor skills. These items represent five separately dimensions of motor functions. Items in prone and supine are combined to represent the dimension of Lying \& Rolling; items in 4-point and kneeling are combined to represent Crawling \& Kneeling dimension; items in Sitting and Standing are examined separately, whereas the items of walking, running, and climbing up the stairs represent the dimension of Walking Running \& Jumping. Assessment of each GMFM item is done by using a 4-point ordinal scale that is consistent.

A value of 0 is given when the child is not able to start (a task that is being tested), a value of 1 is given when the child is able to start $(<10 \%$ of task), a value of 2 is given when children complete some tasks (between $10 \%$ to $<100 \%$ ), while the value of 3 is given when the child has completed all the tasks (in accordance with the description of each criteria). When the test cannot be performed in children, it is marked as NT (not tested) on the scoring sheet. ${ }^{12}$

The examination of GMFM- 88 takes about 45-60 minutes for someone who knows the measuring instrument. This is influenced by the skills of examiner, the child's ability level, and the level of cooperation of each child. GMFM is examined in a comfortable environment for children and an environment which is wide enough to accommodate all the necessary equipment so that children can be examined well and the GMFM measurement can be as accurate as possible. After examination of each item, GMFM scores in every dimension is summed, as well as the total score. The percentage for each dimension and the percentage of GMFM total score are calculated. GMFM-66 has less items, so time needed to do the examination will be shorter, but for calculations, the GMFM-66 required a computer program that is the Gross Motor Ability Estimator (GMAE). With GMAE, score of each item can be calculated and the conversion of ordinal scale into interval scale can be conducted. ${ }^{12}$

Various studies on the validity and reliability of the GMFM has been done in foreign countries and the results are very good, where the GMFM has proved a quite reliable, valid, and responsive to changes in gross motor function in children with CP. ${ }^{12}$ GMFM has been 
translated into various languages, and several validity and reliability of the GMFM translation have been conducted. This study aimed to test the validity and reliability of the GMFM translated into Indonesian, which has never been done before.

\section{METHODS}

The design of this study is cross sectional, with consecutive sampling method. The study populations were $\mathrm{CP}$ children who came to the rehabilitation clinic of the Physical Medicine and Rehabilitation Department of RSCM or those children who came to the Yayasan Pembinaan Anak Cacat (YPAC) Jakarta.

Subjects were between 2 to 15 years old, male or female, whose parents have allowed them to be included in the study and have filled out informed consent forms. Subjects were excluded if suffering from active epilepsy, hydrocephalus, visual disturbances, hearing loss, severe mental retardation, or other neuromuscular and musculoskeletal diseases; and when the subject experienced a fairly severe illness on the day of the test which will affect his/her gross motor function or if the child was not cooperative in the examination.

Subjects were classified according to age, sex, type of $\mathrm{CP}$, anatomical distribution, and the degree of CP. In every subject, gross motor function was assessed through the examination of GMFM's 88-items. Each step was documented with a video camera in order to be re-assessed by the inter-rater.

Criterion validity was tested with the value of correlation coefficient, while the construction validity was tested by comparing the value of each GMFM dimension with the GMFM total score by using corrected Spearman's correlation test. Validity test was also performed for each GMFM dimension. Inter-rater reliability test was done by using unpaired t-test, whereas the internal consistency was tested with the value of Cronbach alpha.

\section{RESULTS}

This study included 31 children with $\mathrm{CP}$, consisted of 19 males and 12 females. The mean age of respondents was 7 years and 11 months, ranged between 2 years and 7 months to 15 years and 8 months. Most of the CP (58.1\%) were caused by perinatal factors. Most of them are spastic CP $(80.65 \%)$, while spastic diplegic was the most common anatomical distribution of CP (45.2\%). A number of $41.9 \%$ subjects were at the GMFCS level IV. Details about the characteristics of study sample can be seen in Table 1 and Table 2 below.

Table 1. Characteristics of study samples

\begin{tabular}{llcc}
\hline & Variable & $\mathrm{N}$ & $\%$ \\
\hline Sex & Male & 19 & 61.3 \\
\multirow{4}{*}{ Etiology } & Female & 12 & 38.7 \\
& Prenatal & 9 & 29.0 \\
\multirow{5}{*}{ Fype } & Perinatal & 18 & 58.1 \\
& Postnatal & 4 & 12.9 \\
\multirow{5}{*}{ Anatomical Distribution } & 25 & 80.65 \\
& Spastic & 5 & 16.13 \\
& Dyskinetic & 1 & 3.2 \\
& Mixed & 0 & 0 \\
& Monoplegic & 14 & 45.2 \\
GMFCS Level & Diplegic & 3 & 9.7 \\
& Hemiplegic & 0 & 0 \\
& Triplegic & 8 & 25.8 \\
& Quadriplegic & 1 & 3.2 \\
& 1 & 5 & 16.1 \\
& 2 & 10 & 32.3 \\
& 3 & 13 & 41.9 \\
& 4 & 2 & 6.5 \\
\hline
\end{tabular}


Table 2. Study sample characteristics of age, body height, body weight, and head circumference

\begin{tabular}{lllllllll}
\hline & Min & Max & Mean & $\begin{array}{l}\text { Std. } \\
\text { Deviation }\end{array}$ & $\begin{array}{l}\text { Skew- } \\
\text { ness }\end{array}$ & $\begin{array}{l}\text { Std. } \\
\text { Error }\end{array}$ & $\begin{array}{l}\text { Curtosis } \\
\text { Std. } \\
\text { Error }\end{array}$ \\
\hline Age (year) & 2.64 & 15.68 & 7.93 & 3.49 & 0.40 & 0.42 & -0.80 & 0.82 \\
Body weight $(\mathrm{kg})$ & 10.5 & 49.00 & 22.18 & 10.13 & 1.41 & 0.42 & 1.51 & 0.82 \\
Body height $(\mathrm{cm})$ & 76 & 151.00 & 113.29 & 17.05 & 0.19 & 0.42 & 0.12 & 0.82 \\
Head circumference $(\mathrm{cm})$ & 45 & 53.00 & 48.82 & 1.85 & 0.13 & 0.42 & 0.11 & 0.82 \\
\hline
\end{tabular}

Table 3 describes the mean value of gross motor skills assessed by the GMFM88. The mean GMFM of study subjects was $58.40 \pm 49.09$. Mean value of $\%$ GMFM on each dimension and mean value of \% total GMFM in children with GMFCS level I CP was greater than the level II, as did the mean value of \%
GMFM in CP GMFCS level II was greater than the level III, GMFCS level III was greater than the level IV, and so forth. This is in accordance with Palisano, ${ }^{17}$ Rosenbaum, ${ }^{18}$ and Hanna et al. ${ }^{19}$ that the GMFM score is inversely correlated to the degree of $\mathrm{CP}$, as being assessed by the GMFCS.

Table 3. Mean Value of Gross Motor Function of CP Children Measured by GMFM-88

\begin{tabular}{lcccccc}
\hline & $\begin{array}{c}\text { Dimension } \\
\mathrm{A}(\%)\end{array}$ & $\begin{array}{c}\text { Dimension B } \\
(\%)\end{array}$ & $\begin{array}{c}\text { Dimension C } \\
(\%)\end{array}$ & $\begin{array}{c}\text { Dimension D } \\
(\%)\end{array}$ & $\begin{array}{c}\text { Dimension E } \\
(\%)\end{array}$ & Total (\%) \\
\hline GMFCS I & 100 & 100 & 97.62 & 76.92 & 81.94 & 91.3 \\
GMFCS II & 93.33 & 91.33 & 77.14 & 49.15 & 48.89 & 71.968 \\
GMFCS III & 94.12 & 91.5 & 60.48 & 26.92 & 19.86 & 59.04 \\
GMFCS IV & 92.16 & 68.21 & 39.01 & 3.75 & 1.91 & 41.008 \\
GMFCS V & 82.36 & 57.5 & 3.57 & 0 & 0 & 28.69 \\
Standard Devia- & & & & & & \\
tion & 4.113 & 11.731 & 13.054 & 10.454 & 18.051 & 49.086 \\
\hline
\end{tabular}

The inter-rater reliability of the test has found no significant differences from the assessments of five GMFM dimensions and all GMFM items, except in items number 18 on the GMFM B dimension ( $\mathrm{p}=0.039)$. Item 18 was the item in which a child is expected to pull himself up from supine position into a sitting position with adequate head control, while the examiner holds the child's hands. The difference of inter-raters' rating is probably caused by the different media assessment, in which the researcher conducted the assessment via direct observation, while the inter-rater used a media of video camera to observe the gross motor function in those children. According to Russell et al., ${ }^{20}$ an assessment through a video camera will greatly depend on the quality of the image, which is strongly influenced by the ability and experience of the video makers, as well as the lighting, the camera angles, and the movement of the test itself. In this study, the images were taken by the researcher, with the help of a tripod.

The internal consistency of GMFM Indonesian version is good, with Cronbach alpha value of 0.884 . Table 4 has shown that the validity of all criterias in GMFM (A, B, C, $\mathrm{D}$ and $\mathrm{E}$ dimensions) are good; with the power of correlation values among inter-items with the total are good into the strong ( $\mathrm{r}=0.523$ to $0.859)$. When one dimension is removed (i.e. dimension A), the value of the total consistency will be better (Cronbach alpha 0.897). 
Table 4. Criterion Validity Test of Each Criteria and Reliability Test of Total GMFM (Item-Total Statistics)

\begin{tabular}{cccccc}
\hline $\begin{array}{c}\text { Criteria } \\
\text { (Dimension) }\end{array}$ & $\begin{array}{c}\text { Scale Mean if } \\
\text { Item Deleted }\end{array}$ & $\begin{array}{c}\text { Scale Variance if } \\
\text { Item Deleted }\end{array}$ & $\begin{array}{c}\text { Corrected Item- } \\
\text { Total Correlation }\end{array}$ & $\begin{array}{c}\text { Squared Multiple } \\
\text { Correlation }\end{array}$ & $\begin{array}{c}\text { Cronbach's } \\
\text { Alpha if Item } \\
\text { Deleted }\end{array}$ \\
\hline A & 170.6526 & 8229.326 & 0.523 & 0.389 & 0.897 \\
B & 183.4690 & 6515.224 & 0.688 & 0.619 & 0.847 \\
C & 211.5642 & 4665.736 & 0.807 & 0.685 & 0.821 \\
D & 241.9974 & 5065.348 & 0.859 & 0.928 & 0.796 \\
E & 245.3323 & 5462.431 & 0.801 & 0.915 & 0.814 \\
\hline
\end{tabular}

Total Cronbach Alpha $=0.884$

Table 5 shows the results of the analysis of construction validity on the criterion of the dimension A. There are several items with not too good validity, which are items number 1, 3, 4, 5, 7, and 9 (item-total correlation coefficients below 0.4). Some items cannot be analyzed because the results were consistent in all 31 respondents either items number 8, 10 and 11 . Yet overall, the reliability of this dimension is good, with Cronbach alpha 0.764 .

Table 5. Validity Test of Each GMFM Item and Reliability Test of Total GMFM of Dimension A (Item-Total Statistics)

\begin{tabular}{ccccc}
\hline Item & $\begin{array}{c}\text { Scale Mean if Item } \\
\text { Deleted }\end{array}$ & $\begin{array}{c}\text { Scale Variance if Item } \\
\text { Deleted }\end{array}$ & $\begin{array}{c}\text { Corrected Item- } \\
\text { Total Correlation }\end{array}$ & $\begin{array}{c}\text { Cronbach's Alpha } \\
\text { if Item Deleted }\end{array}$ \\
\hline V1 & 35.55 & 15.523 & 0.311 & 0.764 \\
V2 & 35.39 & 15.178 & 0.432 & 0.755 \\
V3 & 35.35 & 15.903 & 0.191 & 0.773 \\
V4 & 35.81 & 16.361 & 0.074 & 0.782 \\
V5 & 35.84 & 16.340 & 0.024 & 0.795 \\
V6 & 35.35 & 15.237 & 0.448 & 0.755 \\
V7 & 35.39 & 16.178 & 0.084 & 0.785 \\
V9 & 35.29 & 15.680 & 0.389 & 0.761 \\
V12 & 35.74 & 12.265 & 0.702 & 0.717 \\
V13 & 35.61 & 13.045 & 0.650 & 0.727 \\
V14 & 35.35 & 15.037 & 0.358 & 0.760 \\
V15 & 35.42 & 13.918 & 0.526 & 0.743 \\
V16 & 35.42 & 13.518 & 0.617 & 0.733 \\
V17 & 35.42 & 13.585 & 0.602 & 0.735 \\
\hline
\end{tabular}

Total Cronbach Alpha $=0.764$ 
Construction validity analysis of GMFM dimension $\mathrm{B}$ in table 6 found some items with not too good validity (item-total correlation coefficients below 0.4) which are the items number 18 and 22. Some items cannot be analyzed because the results are consistent in 31 respondents, which are items number 21 and 23. Nevertheless, the overall reliability of GMFM in this dimension is very good with Cronbach's alpha 0.919 .

Table 6. Validity Test of Each GMFM Item and Reliability Test of Total GMFM of Dimension B

\begin{tabular}{ccccc}
\hline Item & $\begin{array}{c}\text { Scale Mean if Item } \\
\text { Deleted }\end{array}$ & $\begin{array}{c}\text { Scale Variance if } \\
\text { Item Deleted }\end{array}$ & $\begin{array}{c}\text { Corrected Item-Total } \\
\text { Correlation }\end{array}$ & $\begin{array}{c}\text { Cronbach's Alpha if } \\
\text { Item Deleted }\end{array}$ \\
\hline V18 & 39.48 & 136.391 & 0.083 & 0.927 \\
V19 & 40.55 & 117.256 & 0.618 & 0.921 \\
V20 & 40.29 & 117.013 & 0.648 & 0.920 \\
V22 & 39.39 & 137.112 & 0.006 & 0.927 \\
V24 & 39.42 & 133.118 & 0.473 & 0.924 \\
V25 & 40.03 & 125.499 & 0.589 & 0.920 \\
V26 & 39.52 & 130.058 & 0.461 & 0.923 \\
V27 & 39.48 & 130.658 & 0.482 & 0.923 \\
V28 & 39.77 & 121.714 & 0.750 & 0.917 \\
V29 & 39.74 & 122.131 & 0.768 & 0.917 \\
V30 & 40.03 & 118.966 & 0.778 & 0.916 \\
V31 & 40.39 & 113.112 & 0.741 & 0.917 \\
V32 & 40.52 & 113.325 & 0.710 & 0.918 \\
V33 & 40.58 & 120.652 & 0.714 & 0.917 \\
V34 & 39.68 & 124.159 & 0.703 & 0.918 \\
V35 & 40.16 & 116.940 & 0.658 & 0.919 \\
V36 & 40.39 & 116.978 & 0.872 & 0.913 \\
V37 & 40.61 & 117.112 & 0.750 & 0.916 \\
\hline
\end{tabular}

Total Cronbach Alpha $=0.919$

Construction validity analysis on GMFM dimensions $\mathrm{C}$ and $\mathrm{D}$ found that the validity of all GMFM items in both dimensions are good. The overall reliability of GMFM in this dimension are very good with the reliability test for dimension $\mathrm{C}$ (table 7, Cronbach's alpha 0.937) and dimension D (table 8, Cronbach's alpha 0.963). 
Table 7. Validity Test of Each GMFM Item and Reliability Test of Total GMFM of Dimension C

\begin{tabular}{ccccc}
\hline Item & $\begin{array}{c}\text { Scale Mean if Item } \\
\text { Deleted }\end{array}$ & $\begin{array}{c}\text { Scale Variance if Item } \\
\text { Deleted }\end{array}$ & $\begin{array}{c}\text { Corrected Item- } \\
\text { Total Correlation }\end{array}$ & $\begin{array}{c}\text { Cronbach's Alpha if } \\
\text { Item Deleted }\end{array}$ \\
\hline V38 & 19.39 & 156.112 & 0.431 & 0.939 \\
V39 & 19.35 & 147.237 & 0.747 & 0.930 \\
V40 & 19.87 & 147.449 & 0.816 & 0.928 \\
V41 & 19.65 & 145.837 & 0.753 & 0.930 \\
V42 & 19.71 & 143.813 & 0.725 & 0.930 \\
V43 & 19.68 & 141.092 & 0.838 & 0.927 \\
V44 & 20.00 & 142.133 & 0.808 & 0.928 \\
V45 & 20.52 & 143.858 & 0.747 & 0.930 \\
V46 & 20.48 & 145.191 & 0.659 & 0.933 \\
V47 & 20.58 & 148.118 & 0.581 & 0.935 \\
V48 & 19.94 & 144.529 & 0.804 & 0.928 \\
V49 & 21.16 & 156.540 & 0.618 & 0.934 \\
V50 & 21.06 & 154.796 & 0.576 & 0.935 \\
V51 & 20.84 & 150.540 & 0.624 & 0.933 \\
\hline
\end{tabular}

Total Cronbach Alpha $=0.937$

Table 8. Validity Test of Each GMFM Item and Reliability Test of Total GMFM of Dimension D

\begin{tabular}{ccccc}
\hline Item & $\begin{array}{c}\text { Scale Mean if Item } \\
\text { Deleted }\end{array}$ & $\begin{array}{c}\text { Scale Variance if } \\
\text { Item Deleted }\end{array}$ & $\begin{array}{c}\text { Corrected Item- } \\
\text { Total Correlation }\end{array}$ & $\begin{array}{c}\text { Cronbach's Alpha if } \\
\text { Item Deleted }\end{array}$ \\
\hline V52 & 6.74 & 90.998 & 0.731 & 0.954 \\
V53 & 7.19 & 87.228 & 0.879 & 0.950 \\
V54 & 7.42 & 88.185 & 0.847 & 0.951 \\
V55 & 7.45 & 89.989 & 0.795 & 0.952 \\
V56 & 7.68 & 89.292 & 0.889 & 0.949 \\
V57 & 8.16 & 104.006 & 0.742 & 0.957 \\
V58 & 8.16 & 104.473 & 0.529 & 0.959 \\
V59 & 7.42 & 88.385 & 0.837 & 0.951 \\
V60 & 7.81 & 92.828 & 0.874 & 0.950 \\
V61 & 7.94 & 96.729 & 0.807 & 0.953 \\
V62 & 7.84 & 93.740 & 0.900 & 0.950 \\
V63 & 7.94 & 97.396 & 0.759 & 0.953 \\
V64 & 7.74 & 91.665 & 0.813 & 0.951 \\
\hline
\end{tabular}

Total Cronbach Alpha $=0.963$

Construction validity of GMFM dimension E in table 9 finds that the validity of all items on the dimension E are good; all are more than 0.4. Only at 1 item, which is in item 82 the correlation values $<0.4$. The overall reliability of this dimension is very good with Cronbach's alpha 0.972 . Standard errors of measurement (SEM) of the Indonesian version for GMFM dimension $\mathrm{A}$ is 2; dimension $\mathrm{B}$ is 3.34; dimension $\mathrm{C}$ is 3.28 ; dimension $\mathrm{D}$ is 2.01 ; dimension of $E$ is 3.03, and for the total GMFM is 16.72. All these values are between 10 to $12 \%$ of the average results of all research subjects. 
Table 9. Validity Test of Each GMFM Item and Reliability Test of Total GMFM of Dimension E

\begin{tabular}{ccccc}
\hline Item & $\begin{array}{c}\text { Scale Mean if Item } \\
\text { Deleted }\end{array}$ & $\begin{array}{c}\text { Scale Variance if Item } \\
\text { Deleted }\end{array}$ & $\begin{array}{c}\text { Corrected Item- } \\
\text { Total Correlation }\end{array}$ & $\begin{array}{c}\text { Cronbach's Alpha if } \\
\text { Item Deleted }\end{array}$ \\
\hline V65 & 11.74 & 288.531 & 0.762 & 0.963 \\
V66 & 11.71 & 288.680 & 0.739 & 0.963 \\
V67 & 11.35 & 294.237 & 0.600 & 0.965 \\
V68 & 11.84 & 288.940 & 0.740 & 0.963 \\
V69 & 12.32 & 288.959 & 0.865 & 0.962 \\
V70 & 12.32 & 288.959 & 0.865 & 0.962 \\
V71 & 12.39 & 292.378 & 0.839 & 0.962 \\
V72 & 12.32 & 288.959 & 0.865 & 0.962 \\
V73 & 12.42 & 295.518 & 0.827 & 0.962 \\
V74 & 12.77 & 316.781 & 0.736 & 0.964 \\
V75 & 12.55 & 297.656 & 0.831 & 0.962 \\
V76 & 12.58 & 299.785 & 0.838 & 0.962 \\
V77 & 12.55 & 298.923 & 0.824 & 0.962 \\
V79 & 12.13 & 285.449 & 0.856 & 0.962 \\
V80 & 12.71 & 310.946 & 0.870 & 0.963 \\
V81 & 12.68 & 307.959 & 0.892 & 0.963 \\
V82 & 12.87 & 323.583 & 0.342 & 0.966 \\
V83 & 12.74 & 312.198 & 0.645 & 0.964 \\
V84 & 12.06 & 291.329 & 0.817 & 0.962 \\
V85 & 12.16 & 296.740 & 0.788 & 0.962 \\
V86 & 12.81 & 316.961 & 0.617 & 0.965 \\
V87 & 12.81 & 316.961 & 0.617 & 0.965 \\
V88 & 12.81 & 316.895 & 0.450 & 0.965 \\
\hline
\end{tabular}

Total Cronbach Alpha $=0.97$

\section{CONCLUSIONS}

GMFM Indonesian version has a criterion validity good to strong with the inter-item with total correlations ( $\mathrm{r}=0.523$ to 0.859 ). In general, all dimensions of GMFM Indonesian version has quite good construct validity. From interrater analysis of GMFM Indonesian version, we did not find any significant differences between the two examiners, means that the GMFM Indonesian version is reliable enough to be examined by different examiners. GMFM Indonesian version has good internal consistency with Cronbach's alpha of 0.884 . Conclusively, GMFM can be used as an instrument for measuring gross motor functions in $\mathrm{CP}$ patients, but sufficient training to obtain the real gross motor ability of children with $\mathrm{CP}$ is needed.

\section{REFERENCES}

1. Yeargin-Allsopp M, Van Naarden Braun K, Doernberg NS, Benedict RE, Kirby RS, Durkin MS. Prevalence of cerebral palsy in 8-year-old children in three areas of the United States in 2002: a multisite collaboration. Pediatrics. 2008;121(3):547-54.

2. Westbom L, Hagglund G, Nordmark E. Cerebral palsy in a total population of 4-11 year olds in southern Sweden prevalence and distribution according to different CP classification systems. BMC Pediatrics 2007;7:41.

3. Pendataan rekam medik Departemen Rehabilitasi Medik-RSUP Cipto Mangunkusumo, Jakarta, 2010.

4. Bax M, Goldstein M, Rosenbaum P, Leviton A, Paneth N. Proposed definition 
and classification of cerebral palsy, April 2005. J. Developmental Medicine \& Child Neurology 2005,47:571-76.

5. Himmelmann K. Cerebral palsy in western Sweden: epidemiology and function. Göteborg: 2006.

6. Styer J, Acevedo. The infant and child with cerebral palsy. In: Tecklin JS, editors. Pediatric physical therapy. 4th edition. USA: Lippincott Williams\&Wilkins; 2008. p. 179-230.

7. Matthews DJ, Wilson P. Cerebral Palsy. In: Molnar GE, Alexander MA, editors. Pediatric rehabilitation. 3rd edition. Philadelphia: Hanley \& Belfus, Inc.; 1999. p. 193-217.

8. Bobath K. A neurophysiological basis for the treatment of cerebral palsy. London: Spastics International Medical Publications; 1980.

9. Bialik GM, Givon U. Cerebral palsy: classification and etiology. Acta Orthop Traumatology Turc 2009:43(92):77-80.

10. The Center for Children with Special Needs Children's Hospital and Regional Medical Center. Cerebral palsy: critical elements of care. 2nd edition. 2002.

11. World Health Organization. ICF international classification of functioning, disability and health. Geneva: World Health Organization; 2001.

12. Russell DJ, Rosenbaum PL, Avery LM, Lane M. Gross motor function measure (GMFM-66 and GMFM-88) user's manual. Clinics in developmental medicine. London: Mac Keith Press; 2002.

13. Beckung E, Carlsson G, Carlsdotter S, Uvebrant $\mathrm{P}$. The natural history of gross motor development in children with cerebral palsy aged 1 to 15 years. Dev Med Child Neurol. 2007 Oct;49(10):7516.

14. Beckung E, Hagberg G, Uldall P, Cans C. Probability of walking in children with cerebral palsy in Europe. Pediatrics 2008;121(1):e187-e192.

15. Bartlett DJ, Palisano RJ. A multivariate model of determinants of motor change for children with cerebral palsy. Phys Ther. 2000;80:598-614.

16. Ross Sandy A, Engsberg Jack R. Relationship between spasticity, strength, gait, and the GMFM-66 in persons with spastic diplegia cerebral palsy. Arch Phys Med Rehabil 2007;88.1114-20.

17. Palisano RJ, Hanna SE, Rosenbaum PL, Russell DJ, Walter SD, Wood EP, et al. Validation of a model of gross motor function for children with cerebral palsy. Phys Ther. 2000;80:974-85.

18. Rosenbaum PL, Walter SD, Hanna SE, Palisano RJ, Russell DJ, Raina $\mathrm{P}$, et al. Prognosis for gross motor function in cerebral palsy: creation of motor development curves. JAMA 2002;288:1357-63.

19. Hanna SE, Bartlett DJ, Rivard LM, Russell DJ. Reference curves for the gross motor function measure: percentiles for clinical description and tracking over time among children with cerebral palsy. Phys Ther. 2008;88:596-607.

20. Russell DJ, Rosenbaum PL, Lane M, Gowland C, Goldsmith CH, Boyce WF, et al.. Training users in the Gross Motor Function Measure: methodological and practical issues. Phys Ther 1994; 74:63 